\section{Arthrite-encéphalite caprine en Algérie}

\author{
H.A. Achour ${ }^{1}$
}

S. Azizen ${ }^{1}$

\section{Y. Ghemmam ${ }^{1}$}

\section{B. Mazari ${ }^{1}$}

ACHOUR (H.A.), AZIZEN (S.), GHEMMAM (Y.), MAZARI (B.). Arthrite-encéphalite caprine en Algérie. Revue Elev. Méd. vét. Pays trop.. 1994,47 (2) : $159-161$

Lors d'une enzootie d'arthrite-encéphalite caprine dans une ferme expérimentale, le virus responsable de cette affection a été isolé d'animaux importés. Une enquête sérologique a alors été entreprise, dans le but de déterminer le taux de prévalence de cette maladie au sein d'autres troupeaux caprins importés, de troupeaux locaux et de troupeaux mixtes. Des sérologies positives ont été trouvées à des taux relativement élevés dans les élevages importés et les élevages mixtes. En revanche, tous les troupeaux locaux testés sont à sérologie négative, ce qui laisse supposer que l'arthrite-encéphalite caprine n'existait pas en Algérie avant l'importation d'animaux reproducteurs à haut potentiel génétique.

Mots clés : Caprin - Virus arthrite-encéphalite caprine - Epidémiologie Enquête sérologique - Algérie.

\section{Introduction}

Dès 1986, l'Algérie a entrepris un vaste programme d'importation d'animaux à haut potentiel génétique en vue d'améliorer les performances zootechniques des élevages caprins. C'est ainsi qu'entre 1986 et 1988,3542 caprins de race Alpine et Saanen ont été importés de France.

En décembre 1987, on signalait l'apparition de polyarthrites associées à des avortements dans un élevage caprin expérimental de la wilaya de Laghouat. II s'agissait d'un élevage parfaitement conduit, composé de 186 chèvres Alpine et de 48 chèvres de race locale Arabia, dont on voulait comparer les performances zootechniques. Les animaux malades présentaient des hypertrophies articulaires, notamment au niveau des genoux, ce qui les empêchait de se déplacer et de s'alimenter convenablement. L'administration par le vétérinaire traitant de différents antibiotiques n'a apporté aucune amélioration. L'évolution de la maladie se fait sans hyperthermie, la morbidité au sein du troupeau étant de l'ordre de 20 p. 100 . Une chèvre alpine âgée de 3 ans, présentant une hypertrophie des articulations du genou, faible et très amaigrie, a été amenée vivante au laboratoire, sacrifiée et autopsiée. Un examen méticuleux des différents viscères n'a mis en évidence aucune liaison particulière. Seules les articulations du carpe présentaient un œdème des tissus mous péri-articulaires. La membrane synoviale était de couleur rouge-brun, épaissie et présentait des

1. Laboratoire vétérinaire régional, 7 rue du stade, 15.100 Draa-BenKhedda, wilaya de Tizi-Ouzou, Algérie.

Reçu le 8.10.1993, accepté le 26.4.1994 pétéchies. On a également remarqué la présence de grains riziformes de couleur blanchâtre au niveau des gaines tendineuses.

\section{Matériel et méthodes}

A la suite des observations, dans cet élevage pilote, des manifestations cliniques et nécrospiques pouvant être rapportées à l'arthrite-encéphalite caprine et après isolement du virus, des examens sérologiques ont été entrepris dans cet élevage, ainsi que dans d'autres exploitations où des problèmes sanitaires similaires commençaient à être rencontrés.

De 1987 à 1990, des prélèvements sanguins en provenance de plusieurs wilayates (départements) ont été testés en immunodiffusion en gélose, vis-à-vis d'un antigène Visna-Maedi (souche WLC1). Ce virus, agent de la pneumonie progressive du mouton, présente, avec le virus de l'arthrite et de l'encéphalite caprine (CAEV), une communauté antigénique en ce qui concerne la glycoprotéine d'enveloppe (gp135) et la protéine du core (p 28). Le test d'immunodiffusion en gélose avec cet antigène VisnaMaedi met surtout en évidence des anticorps circulants anti p 28 et donne, en diagnostic de groupe, des résultats équivalents à ceux obtenus avec un antigène CAEV $(2,3,5)$.

Dans le cadre de cette enquête sérologique, 9510 sérums ont été testés. Au total, 14 troupeaux d'animaux importés ont été contrôlés et certains animaux ont fait l'objet de plusieurs examens sérologiques ; les jeunes caprins nés en Algérie ont été également testés. Seulement 1262 caprins sur les 3542 animaux importés ont été réellement examinés. Ces troupeaux sont constitués d'animaux en provenance de différentes régions de France, la majorité provenant de Haute Provence et de Touraine. Par ailleurs, 299 troupeaux ne comportaient que des animaux locaux et 38 troupeaux locaux, où des caprins importés ont été introduits (élevages mixtes), ont également fait l'objet d'un examen sérologique.

\section{Résultats (photos 1, 2 et 3)}

Les résultats sérologiques obtenus lors de cette enquête font ressortir les faits suivants :

- tous les troupeaux locaux examinés durant la période de l'enquête sont à sérologie négative (tabl. I) ;

- tous les troupeaux importés sont à sérologie positive Ce taux de positivité au sein de chaque troupeau varie de 12,1 à 35,2 p. 100 . Rapportée au nombre total d'animaux importés examinés par année, cette séro-incidence est de l'ordre de 12 à 27 p. 100 (tabl. II) ;

- tous les troupeaux mixtes testés ont été trouvés sérologiquement positifs à des taux variant de 4,9 à 47,7 p. 100. Ces taux de séropositivité sont plus élevés dans les 


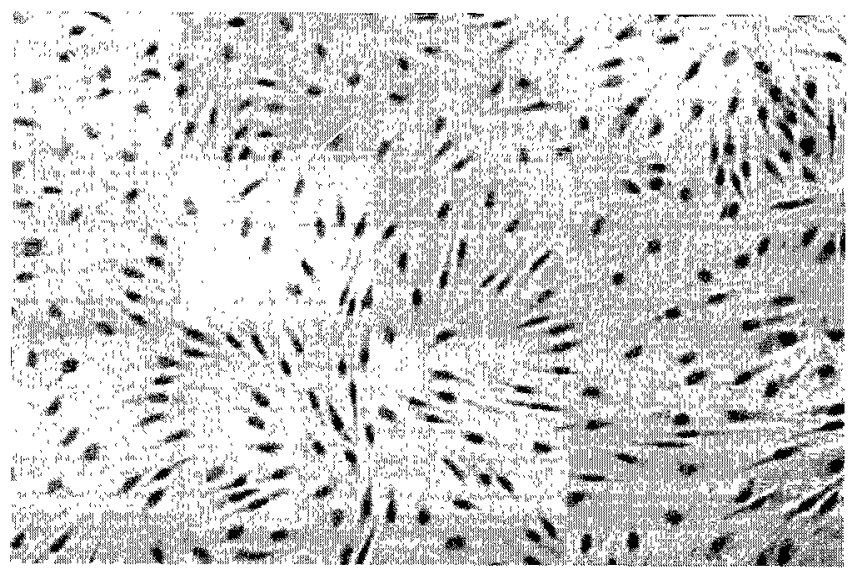

Photo 1 : Culture cellulaire de membrane synoviale de chevreau au $9 e$ passage-témoin non infecté $(x$ 175).

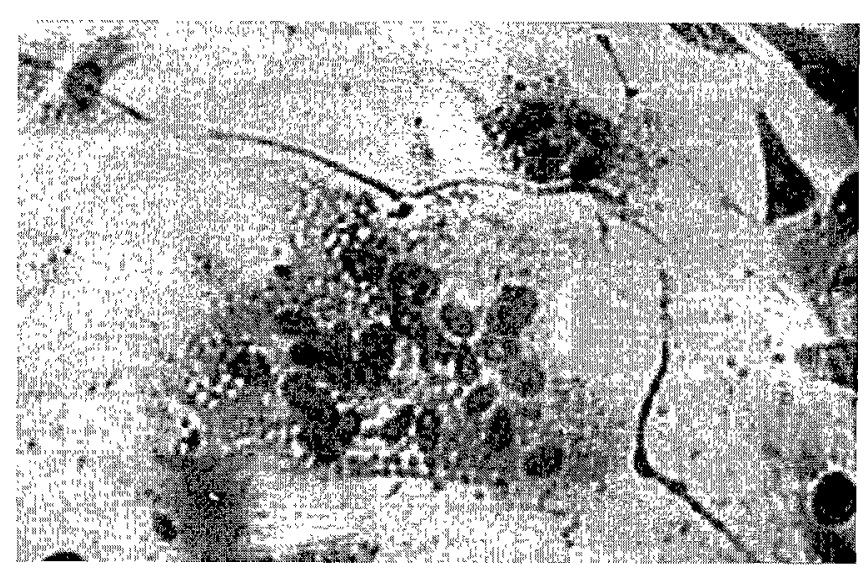

Photo 2 : Formation de syncitia sur culture cellulaire de membrane synoviale de chevreau (souche virale 63/87) (x 335).

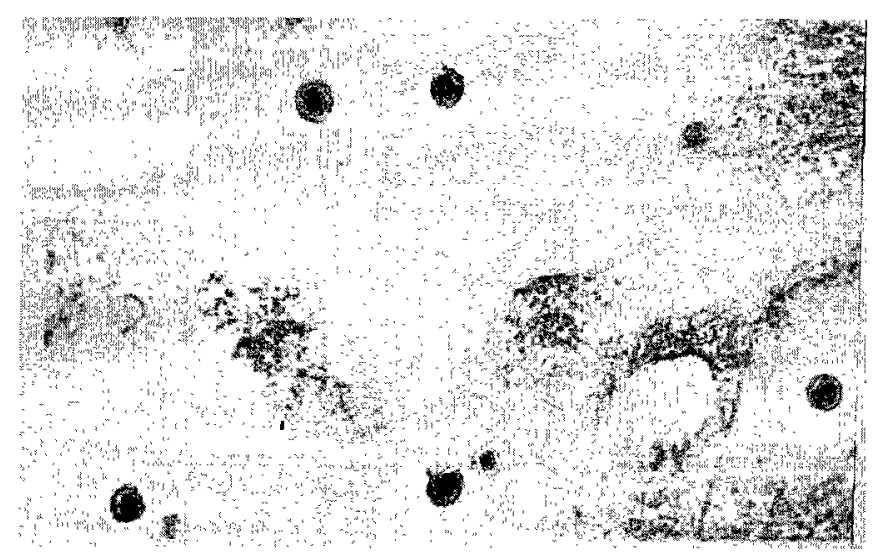

Photo 3 : Particules virales enveloppées et présentant un core dense aux électrons dans les débris cellulaires ( $x 55$ 000, nicroscope électronique). troupeaux où les animaux importés ont été introduits dès leur arrivée en Algérie. Rapportée au nombre total d'animaux examinés par année, cette séro-incidence est de l'ordre de 20 à 22 p. 100 (tabl. III).

Plusieurs de ces troupeaux ont été examinés sur 2 ou 3 ans et on a constaté des sérologies positives sur des animaux de race locale qui, lors du premier examen, étaient négatifs, ce qui indique une diffusion du virus des animaux importés vers les animaux locaux.

\section{Discussion}

Les résultats obtenus dans le cadre de ce travail montrent que le virus de l'arthrite et de l'encéphalite caprine est présent en Algérie et qu'il y a été introduit par les caprins importés entre 1986 et 1988 . Comme beaucoup de ces animaux sont destinés à être utilisés comme reproducteurs dans des pépinières à chevrettes ou comme géniteurs dans les élevages locaux, il y a risque de diffusion de ce virus dans les élevages locaux indemnes. Pour cette raison, il faut éviter que des animaux malades ne soient introduits dans des élevages locaux et mettre en place, dans les élevages infectés, des programmes d'assainissement sur le modèle de ceux déjà pratiqués dans d'autres pays $(1,4,5)$. Une tentative de mise en place d'un tel programme a déjà eu lieu dans la ferme expérimentale de Laghouat. Les résultats obtenus après 3 années de suivi sont demeurés médiocres. II a été très difficile de faire admettre au personnel d'entretien le strict respect des mesures prophylactiques préconisées. Les échecs enregistrés étaient dus, dans la plupart des cas, au non-respect de ces recommandations.

Cette méthode d'assainissement des troupeaux est très contraignante. Pour que ce programme réussisse, il faudrait, d'une part que les éleveurs y participent pleinement, en prenant notamment conscience du danger encouru par leurs élevages, et, d'autre part, que l'Etat intervienne financièrement en assurant le remplacement des animaux abattus dans le cadre de la prophylaxie sanitaire.

\section{Conclusion}

Dorénavant, les autorités vétérinaires nationales devront tenir compte de celte maladie, tant dans les élevages locaux, en procédant à des enquêtes ponctuelles, que lors des importations de caprins reproducteurs, afin d'éviter toute nouvelle introduction de cette infection.

En raison de la forte prévalence de l'infection dans de nombreux pays exportateurs de caprins reproducteurs, les animaux importés devront tous provenir de troupeaux officiellement indemnes d'arthrite et d'encéphalite caprine. Ils seront soumis, lors de la quarantaine, à un examen clinique et sérologique, tout en ne perdant pas de vue qu'un pourcentage non négligeable d'animaux cliniquement atteints peuvent être séronégatifs. Toute séropositivité d'un animal doit être interprétée en diagnostic de groupe et tous les animaux en provenance du même troupeau doivent être considérés comme contaminés. 
TABLEAU I Elevages locaux : examens sérologiques effectués entre 1987 et 1990.

\begin{tabular}{|c|c|c|c|c|}
\hline Année & Troupeaux & Animaux testés & Séropositifs & Séro-incidences (p. 100) \\
\hline 1987 & 72 & 1587 & 0 & 0 \\
1988 & 77 & 1200 & 0 & 0 \\
1989 & 97 & 2072 & 0 & 0 \\
1990 & 53 & 1440 & 0 & 0 \\
\hline
\end{tabular}

TABLEAU II Elevages importés : examens sérologiques effectués entre 1987 et 1990.

\begin{tabular}{|c|c|c|c|c|}
\hline Année & Troupeaux & Animaux testés & Séropositifs & Séro-incidences (p. 100) \\
\hline 1987 & 3 & 647 & 106 & 16 \\
1988 & 3 & 600 & 161 & 27 \\
1989 & 7 & 773 & 92 & 12 \\
1990 & 1 & 33 & 04 & 12 \\
\hline
\end{tabular}

TABLEAU III Elevages mixtes : examens sérologiques effectués entre 1987 et 1990.

\begin{tabular}{|c|c|c|c|c|}
\hline Année & Troupeaux & Animaux testés & Séropositifs & Séro-incidences $(p .100)$ \\
\hline 1987 & - & - & - & - \\
1988 & 7 & 333 & 71 & 21 \\
1989 & 18 & 508 & 104 & 20 \\
\\
\hline
\end{tabular}

\section{Remerciements}

Les auteurs remercient vivement les Drs MARFOUA, ROUABAH, BENCHEIKH EL FEGOUN, ABABSA, BENALI, LOUNIS, KEFFI, TAFER, CHALA et ABTOUT pour avoir transmis les prélèvements sanguins ; les Drs ASSO (ENV Lyon) et CHAPPUIS (IFFA Mérieux) pour les avoir initiés aux techniques de diagnostic des lentivirus et leur avoir fourni l'antigène Visna-Maedi (souche WLC1). Nous remercions aussi Mme HADJLOUM pour son aide.

\section{Bibliographie}

1. ADAMS (D.S.), KLEJVER-ANDERSON (P.), CARLSON (S.L.), McGUIRE (T.C.), GORHAM (J.R.). Transmission and control of caprine arthritis encephalitis virus. Am. J. vet. Res., 1983, 44 (9) : 1670-1675.

2. GIANGASPERO (M.), VANOPDENBOSH (E.), NISHIKAWA (H.). Lentiviral arthritis and encephalitis in goats in north west Syria. Revile Élev. Méd. vét. Pays trop., 1992, 45 (3-4): 241.

3. GOGOLEWSKI (R.P.), ADAMS (D.S.). MLGUIRE (T.C.). BANKS (K.L.), CHEEVERS (W.P.). Antigenic cross reactivity between caprine arthritis encephalitis, visna and progressive pneumonia viruses involves all virion-associated proteins and glycoprotcins. J. gen. Virol.. 1985, 66: 12331240 .
4. MacKENZIE (R.W.), OLIVER (R.E.), ROONEY (J.P.), HAGEI (H.). A successful attempt to raise goat kids free of infection with caprine arthritis encephalitis virus in endemically infected goat herd. N.Z. vet.J., 1987, 35: 184-186.

5. VITU (C.), RUSSO (P.). Application d'un test ELISA à la sćrologic du virus des arthrites et encéphalites caprines. Comparaison avec les tests d'immunodiffusion en gélose. I $n$ : Les maladies de la chèvre. Niort, Colloques de l'INRA, 1984, 28: 647-650.

ACHOUR (H.A.), AZIZEN (S.), GHEMMAM (Y.), MAZARI (B.). Caprine arthritis-encephalitis in Algeria. Revue Élev. Méd. vét. Pays trop., 1994, 47 (2): 159-161

During an outbreak of caprine arthritis-encephalitis on an experimental farm, the virus responsible for this disease was isolated from imported animals. A serological survey was then carried out with the purpose of determining the prevalence of the disease among other imported herds of goats, local herds and mixed herds. Positive serological results were found at relatively high levels in both imported and mixed herds. All the local herds. however, yielded negative serological results, suggesting that caprine arthritis-encephalitis did not exist in Algeria before the importation of reproductive animals with a high genetic potential.

Key words : Goat - Caprine arthritis-encephalitis virus - Epidemiology Serological survey - Algeria. 